American Journal of Biochemistry and Biotechnology 6 (3): 204-212, 2010

ISSN 1553-3468

(C) 2010 Science Publications

\title{
Impact of L-Carnitine and Cinnamon on Insulin-Like Growth Factor-1 and Inducible Nitric Oxide Synthase Gene Expression in Heart and Brain of Insulin Resistant Rats
}

\author{
Mona A. Mohamed \\ Biochemistry Division, Department of Chemistry, Faculty of Science, \\ Al-Azhar University, Cairo, Egypt
}

\begin{abstract}
Problem statement: Evaluate the effects of daily administration of L-carnitine and cinnamon extract for two weeks on the expression of Insulin-like Growth Factor-1 (IGF-1) and inducible Nitric Oxide Synthase (iNOS) genes in cardiac and brain tissues of rats with Insulin Resistance (IR). Approach: Rats were divided into 4 groups (8 animals each): Group (1) rats fed control diet (60\% starch) as control while groups (2, 3 and 4) fed high fructose diet (60\% fructose). At the beginning of the $3 \mathrm{rd}$ week of feeding, rats of group (3) were treated with L-carnitine $\left(300 \mathrm{mg} \mathrm{kg}^{-1}\right.$ body weight/day, i.p.) and animals of group (4) received a daily oral dose of cinnamon aqueous extract $\left(0.5 \mathrm{~mL} \mathrm{rat}{ }^{-1}\right)$. The animals were maintained in their respective groups for 4 weeks. Results: Feeding high fructose diet causes significant reduction in Insulin Receptor Substrate-1 (IRS-1) (amounted 30.65\%) and elevation in iNOS expression (reached 51\%) in the cardiac tissues as compared to control. In brain tissues, the IGF-1 mRNA was reduced in fructose loaded groups (28.81\%). Administration of either L-carnitine or cinnamon extract significantly improves the expression of the cardiac studied genes but with no effects on the brain tissues. Conclusion: The present study illustrated that CE was more potent than L-carnitine in improving the IR.
\end{abstract}

Key word: Insulin resistance, insulin-like growth factor-1, inducible nitric oxide synthase, insulin receptor substrate-1

\section{INTRODUCTION}

Fructose consumption has largely increased most likely as a result of this increased use of high fructose corn syrups and pre-packaged foods that contains between $55-90 \%$ fructose. Diets specifically high in fructose have been shown to contribute to a metabolic disturbance in animal models resulting in weight gain, hyperlipidemia and insulin resistance (Hwang et al., 1987). Insulin Resistance (IR) is accompanied by deleterious metabolic consequences including hyperinsulinemia, hyperglycemia, glucose intolerance and hypertriglyceridemia in rodents. Therefore fructose-fed rat is used as an animal model of IR (Kannappan et al., 2006).

Insulin is known to promote the actions of various growth factors and increase in cell growth in multiple cell types (Wang et al., 2006). Insulin-like Growth Factor-1 (IGF-1) is synthesized mainly by the liver and kidneys but also, in a paracrine and autocrine way, by endothelial and vascular smooth muscle cells and cardiac myocytes (Conti et al., 2001).

Several lines of evidence indicate that IR or hyperinsulinemia may be causal factors in the development of thick left ventricular walls and left ventricular hypertrophy. Insulin at high concentrations is capable of inducing hypertrophic effects via IGF-1 receptor (which are abundant in the heart), but also at low concentrations via the insulin receptor (Hill and Milner, 1985; Frystyk and Orskov, 2004).

Some investigators revealed a correlation between IR and defects of the Nitric Oxide (NO) system (Shinozaki et al., 19991; Kuboki et al., 2000). Inducible Nitric Oxide Synthase (iNOS; EC 1.14.13.39) is assumed to be one of the candidates that mediate inflammation involved in insulin resistance (Fujimoto et al., 2005). Among the multiple alterations associated with heart failure, the induction of myocardial expression of iNOS has gained particular attention because this high output isoform of NO synthases releases high levels of NO product, which in cardiac myocytes is known to induce apoptosis (Taimor et al., 2001). In view of this detrimental potential, the concept was developed that cardiac iNOS induction might be an important factor in the pathogenesis of heart failure.

Although the effects of the high fructose diet on the different biochemical parameters in serum and tissues 
have been discussed, little is known about its effect on brain tissue. There is a substantial literature indicates that the chemistry and the function of both the developing and mature brain can be influenced by the diet (Kurban et al., 2007).

Cheng et al. (2000) had shown that IGF-1 is a key regulator of glucose transport and utilization in the developing murine brain. They also demonstrated that the caloric content and macronutrient composition of the diet exert independent effects on brain IGF-1 gene expression.

Pharmacological therapy is a critical step in the management of patients with metabolic syndrome when life style modifications fail to achieve the therapeutic goals (Deedwania and Gupta, 2006). Much scientific research has focused on the health benefits of herbs and spices. Some of these benefits are broad-based, but others are specific to one or a few physiological functions in the body. Naturally-occurring compounds that have been shown to improve insulin sensitivity include L-carnitine and cinnamon. L-carnitine ( $\beta$ hydroxy-6-trimethyl aminobutarate) is a ubiquitous constituent of mammalian plasma and tissues, mainly distributed among skeletal and cardiac muscles. Carnitine is supplied to the body through dietary sources (e.g., meat and dairy products) and by biosynthesis from lysine and methionine. Carnitine transports long chain fatty acids across the inner mitochondrial membrane into the matrix for $\beta$ oxidation and has effects on oxidative metabolism of glucose in tissues (Rajasekar and Anuradha, 2007).

Cinnamon (Cinnamon zeylanicum) is a spicy, which is added to food preparations to impart taste and aroma. Cinnamon has insulin-potentiating properties and may be involved in the alleviation of the signs and symptoms of diabetes and cardiovascular disease related to IR (Anderson, 2008).

Considering all these, the present study was initiated to evaluate the effects of L-carnitine and cinnamon extract supplementation on the expression of IGF-1 and iNOS genes in heart and brain tissues of rats fed high fructose diet as a well-characterized model of IR.

\section{MATERIALS AND METHODS}

Chemicals: L-carnitine, other chemicals and solvents were of high analytical grade and were purchased from Sigma Chemical Company.

Cinnamon extract: Cinnamon bark (Cinnamon zeylanicum) was purchased from the local market and extracted according to the method of Kannappan et al.
(2006). This extract was diluted with water (1:10) and was administered orally to rats.

Animals and treatment: Male Wister rats at the age of 22 weeks $(\mathrm{n}=32)$ and body weight ranging from 120 $170 \mathrm{~g}$ were obtained from the breeding unit of the Egyptian Organization for Biological Products and Vaccines (Helwan, Egypt). Rats were housed 2/cage under controlled condition $12 \mathrm{~h}$ light/12 h dark cycle. All animals received standard pellet diet for one week and water ad libitum.

After acclimatization, animals were divided into the following groups consisting of 8 rats each: Group 1: (Con)/control animals received the control diet which

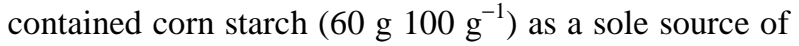
carbohydrate. Group 2: (HFD)/Fructose-fed rats received a high fructose diet $\left(60 \mathrm{gm} 100 \mathrm{~g}^{-1}\right)$. Group 3: $(\mathrm{HFD}+\mathrm{CAR}) /$ fructose-fed animals received the fructose-diet and treated with L-carnitine $\left(300 \mathrm{mg} \mathrm{kg}^{-1}\right.$ body wt/day, i.p.) at the beginning $3 \mathrm{rd}$ week of experimental period. Group 4: (HFD + CE)/Fructosefed rats received a daily oral dose of CE extract $(0.5 \mathrm{~mL}$ $\mathrm{rat}^{-1}$ ) from the $3 \mathrm{rd}$ week of experimental period.

The animals were maintained in their respective groups for 4 weeks and body weight changes were recorded weekly. At the end of the experimental period, animals in all groups were weighed and blood samples were taken from the retro-orbital venous plexus under light ether anesthesia after a fast of $12 \mathrm{~h}$. Serum was separated by centrifuging blood samples at $3000 \mathrm{rpm}$ for $10 \mathrm{~min}$. Serum samples were aliquoted and stored at $-20^{\circ} \mathrm{C}$ until analysis, except for glucose which was determined on the same day. After blood collection, all animals were sacrificed by decapitation and for each animal heart and brain were excised, rinsed with shield saline, weighed and rapidly frozen in liquid nitrogen then stored at $-70^{\circ} \mathrm{c}$ until assayed.

Serum analysis: Serum was used for determination of glucose and Triacylglycerol (TG) according to the methods described by Mahfouz et al. (2010). The remaining part of serum was used for determination of insulin which was assayed by monoclonal immunoradiometric assay using kit supplied by Diagnostic Products Corporation (DPC) according to Marschner et al. (1974). Homeostasis Model Assessment (HOMA) correlates positively with insulin-resistance and was calculated according to Matthews et al. (1985).

Extraction of tissue lipids: Extraction was carried out according to the procedure of Refaie et al. (2005). Briefly, total lipids from tissues were extracted by homogenization with chloroform and methanol (2:1). 
The extraction solvent was evaporated and lipids resuspended in methanol. Cholesterol and triacylglycerol concentrations were assayed according to the method of Yousef et al. (2006) and Foster and Dunn (1973).

Determination of tissue MDA and NO: The concentrations of Malondialdehyde (MDA) and nitric oxide (NO as nitrite and nitrate) were estimated in the whole tissue homogenate $(5 \%)$ according to the methods of Esterbauer and Cheeseman (1990) and Moshage et al. (1995), respectively.

Gene expression of IGF-1 and iNOS by RT-PCR: Total RNA was extracted from the tissues by the acid guanidinum thiocyanate-phenol chloroform method of Shaker et al. (2009). The sequence of the primers used to amplify IGF-1 and iNOS genes was illustrated in Table 1.

Reverse transcription-polymerase chain reaction was done using the RT-PCR kit (Promega, Madison, WI). Briefly, 1ug extracted RNA, 6ul dNTP, 6ul 5x buffer and $30 \mathrm{pM}$ specific downstream primer were brought up to a total volume of 28 ul. The mixture was heated at $65^{\circ} \mathrm{C}$ for $5 \mathrm{~min}$. and chilled on ice for $5 \mathrm{~min}$. Exactly, $0.5 \mu \mathrm{L}$ RNasin and 1ul AMV were added and the mixture was incubated at $42^{\circ} \mathrm{C}$ for $2 \mathrm{~h}$. Then, $5 \mu \mathrm{L}$ of cDNA was added to $200 \mu \mathrm{M}$ dNTP, 2.5U Taq polymerase and $3.3 \mathrm{nM} \mathrm{MgCl}$ in a final volume of 30 $\mu \mathrm{L}$. The reaction mixture was placed in a Hybaid Express thermal cycler for $3 \mathrm{~min}$ at $95^{\circ} \mathrm{C}$ and then subjected for 32 cycles of $95^{\circ} \mathrm{C}$ for $1.5 \mathrm{~min}, 55^{\circ} \mathrm{C}$ for 1 min, $72^{\circ} \mathrm{C}$ for $1.5 \mathrm{~min}$ and a final step at $72^{\circ} \mathrm{C}$ for 10 min. All the PCR products were applied to specified wells into an ethidium bromide-stained $2 \%$ agarose gel in known order, then semi-quantities using the gel documentation system (Bio Doc Analyzer) supplied by Biometra. The content of IGF-1 and iNOS mRNA were calculated and expressed as cDNA relative densitometric units (ratio of IGF-1 or iNOS cDNA/ $\beta$-actin).

Cardiac Insulin Receptor Substrate-1 (IRS-1): Western blot analysis was used to determine the cardiac (IRS-1) (ug $\mathrm{mL}^{-1}$ ) according to the method of Bezerra et al. (2000). For brain tissue, IRS-1 was not performed.

Table 1: Sequence of the primers used to amplify IGF-1, iNOS and $\beta$ actin genes

\begin{tabular}{ll}
\hline Gene & Primer sequence \\
\hline IGF-1: Forward & GTGTGGACCGAGGGGCTTTTACTTC \\
Reverse & GCTTCAGTGGGGCACAGTACATCTC \\
iNOS: Forward & GGCTTGCCCCTGGAAGTTTCTCTTCAAAGTC \\
Reverse & AAGGAGCCATAATACTGGTTGATG \\
B-actin: Forward & TGTTGTCCCTGTATGCCTCT \\
Reverse & TAATGTCACGCACGATTTCC \\
\hline
\end{tabular}

Statistical analysis: All results were expressed as the mean \pm SD. Statistical analysis was performed with Statistical Package for the Social Science for Windows (SPSS, version 11.0, Chicago, IL, USA). The data were analyzed by one-way Analysis of Variance (ANOVA). To compare the difference among the groups, post hoc testing was performed by the Bonferroni test. The pvalue $<0.05$ was considered statistically significant (Dawson, 2000).

\section{RESULTS}

At the end of the experiment, the percentage change in the body weight gain and the relative heart and brain weights in rats of the studied groups were not statistically significant, compared to control rats (Table 2).

Data in Table 3 illustrate that the serum levels of glucose, insulin and HOMA index as well as triacylglycerol were significantly elevated $(\mathrm{p}<0.0001)$ in HFD group after 4 weeks of fructose-feeding, compared to control group. Administration of Lcarnitine for 2 weeks caused significant reductions in glucose, HOMA and TG $(\mathrm{p}<0.0001)$, while insulin level did not change significantly, compared to HFD group. Cinnamon treated rats reduced these studied parameters to the normal control values, except serum cholesterol which did not altered in all groups.

Concentrations of cholesterol and triacylglycerol in addition to MDA and NO products in cardiac and brain tissues were illustrated in Table 4 . Feeding rats with HFD did not affect significantly the concentrations of both cardiac and brain cholesterol and NO product, compared to control rats. The levels of cardiac TG and MDA were elevated significantly $(\mathrm{p}<0.0001)$, while no changes were observed in the brain tissues, compared to control.

With regard to carnitine treated group, all the studied cardiac parameters were non significantly changed, except the cardiac concentration of MDA which showed significant reduction, compared to HFD groups $(p<0.001)$ and was toward the control value. In addition, carnitine reduced brain cholesterol level ( $\mathrm{p}<0.001)$, compared to HFD group.

Cinnamon treatment did not affect cardiac cholesterol and NO levels, but it significantly reduced the cardiac levels of TG and MDA $(p<0.001)$, compared to HFD group. On the other hand, cinnamon reduced significantly the levels of cholesterol $(\mathrm{p}<0.0001$ and 0.001$)$ and NO $(\mathrm{p}<0.0001$ and 0.001), compared to control and HFD groups, respectively. 
Am. J. Biochem. \& Biotech., 6 (3): 204-212, 2010

Table 2: Body weight gain $\%$ and organs weights (mean \pm SD) in different studied groups

\begin{tabular}{lllll}
\hline Weights (\%) & Con & HFD & HFD +CAR & HFD +CE \\
\hline Body wt. gain & $20 \pm 3.47$ & $19 \pm 6.13$ & $27 \pm 2.92$ & $20 \pm 6.03$ \\
Relative heart wt. & $0.34 \pm 0.04$ & $0.32 \pm 0.02$ & $0.31 \pm 0.03$ & $0.35 \pm 0.03$ \\
Relative brain wt. & $0.84 \pm 0.12$ & $0.79 \pm 0.07$ & $0.80 \pm 0.11$ & $0.85 \pm 0.14$ \\
\hline
\end{tabular}

Relative organ wt. \% = (organ wt / body wt) X 100

Table 3: Metabolic serum parameters (mean $\pm \mathrm{SD}$ ) in the different studied groups

\begin{tabular}{lllll}
\hline Parameters & Con & HFD & HFD +CAR & HFD +CE \\
\hline Glucose $\left(\mathrm{mg} \mathrm{dL}^{-1}\right)$ & $92.20 \pm 9.78$ & $155.06 \pm 16.80^{\mathrm{a}}$ & $97.43 \pm 8.30^{\mathrm{b}}$ & $89.19 \pm 13.50^{\mathrm{b}}$ \\
Insulin $\left(\mu \mathrm{IU} \mathrm{m} \mathrm{L}^{-1}\right)$ & $19.46 \pm 3.60$ & $36.29 \pm 6.70^{\mathrm{a}}$ & $28.47 \pm 6.90^{\mathrm{a}}$ & $20.04 \pm 4.20^{\mathrm{b}}$ \\
HOMA & $4.44 \pm 0.60$ & $13.88 \pm 2.20^{\mathrm{a}}$ & $6.86 \pm 1.60^{\mathrm{a}, \mathrm{b}}$ & $4.43 \pm 1.20^{\mathrm{b}}$ \\
Cholesterol $\left(\mathrm{mg} \mathrm{d} \mathrm{L}^{-1}\right)$ & $75.27 \pm 10.30$ & $84.28 \pm 12.40$ & $76.58 \pm 10.20$ & $77.43 \pm 10.70$ \\
TG $\left(\mathrm{mg} \mathrm{d} \mathrm{L}^{-1}\right)$ & $78.30 \pm 12.20$ & $165.78 \pm 13.50^{\mathrm{a}}$ & $95.92 \pm 9.80^{\mathrm{a}, \mathrm{b}}$ & $79.92 \pm 10.50^{\mathrm{b}}$ \\
\hline
\end{tabular}

${ }^{a}: \mathrm{p}<0.0001$ Vs CON; ${ }^{b}: \mathrm{p}<0.0001$ Vs. HFD

Table 4: Concentration of cholesterol, TG $\left(\mathrm{mg} \mathrm{g}^{-1}\right)$ and MDA $\left(\mu \mathrm{mol} \mathrm{g}^{-1}\right)$ as well as NO product $\left(\mu \mathrm{M} \mathrm{g}^{-1}\right)(\mathrm{mean} \pm \mathrm{SD})$ in cardiac and brain tissues

\begin{tabular}{lllc}
\hline Parameters & Con & HFD & HFD +CAR \\
\hline Cardiac tissues & & & $2.98 \pm 0.56$ \\
Cholesterol & $2.34 \pm 0.61$ & $23.10 \pm 1.65^{\mathrm{a}}$ & $2.64 \pm 0.51$ \\
TG & $19.53 \pm 1.9$ & $41.19 \pm 4.54^{\mathrm{a}}$ & $22.65 \pm 3.75$ \\
MDA & $22.10 \pm 3.47$ & $1.17 \pm 0.27$ & $28.19 \pm 1.66^{\mathrm{a}, \mathrm{b}}$ \\
NO & $0.97 \pm 0.12$ & & $1.21 \pm 0.21$ \\
Brain tissues & & $14.50 \pm 1$ & $28.73 \pm 2.89^{\mathrm{a}, \mathrm{b}}$ \\
Cholesterol & $13.10 \pm 1.50$ & $14.8 \pm 1.19$ & $1.34 \pm 0.46$ \\
TG & $16.60 \pm 1.40$ & $40.23 \pm 3.50$ & $12.50 \pm 0.46^{\mathrm{b}}$ \\
MDA & $35.30 \pm 4.90$ & $2.85 \pm 0.22$ & $41.50 \pm 0.54$ \\
NO & $3.30 \pm 0.68$ & & $10.16 \pm 1.30^{\mathrm{a}, \mathrm{b}}$ \\
\end{tabular}

${ }^{\mathrm{a}}: \mathrm{p}<0.0001$ Vs CON; ${ }^{\mathrm{b}}: \mathrm{p}<0.001$ Vs HFD

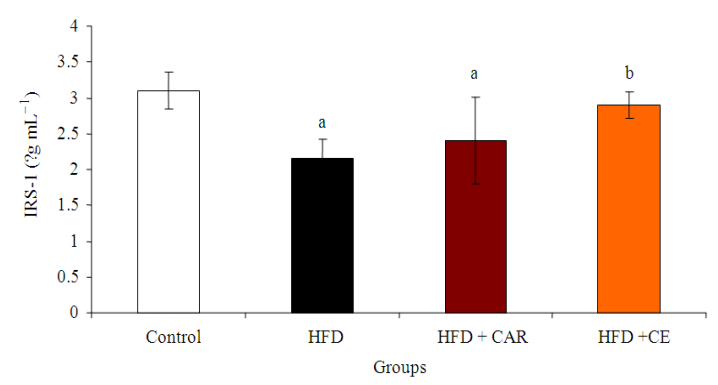

Fig. 1: Effects of high fructose diet, L-carnitine and cinnamon extract on cardiac IRS-1 level

Significant reduction was observed in the levels of cardiac IRS-1 in rats fed high fructose diet $(\mathrm{p}<0.0001)$, compared to control rats. Carnitine administration slightly elevated the level of IRS-1 toward control but this elevation was not significant as compared to HFD group. Administration of cinnamon improved the receptor level $(\mathrm{p}<0.001)$, compared to HFD group (Fig. 1).

Figure 2 illustrate that there was significant elevation in the expression of cardiac IGF-1 in groups treated with carnitine and cinnamon $(\mathrm{p}<0.001)$, compared to HFD group. The expression of iNOS was significantly elevated $(\mathrm{p}<0.0001)$ in HFD group, compared to control. Oral administration of cinnamon reduced significantly $(\mathrm{p}<0.001)$ the iNOS expression, compared to HFD group.

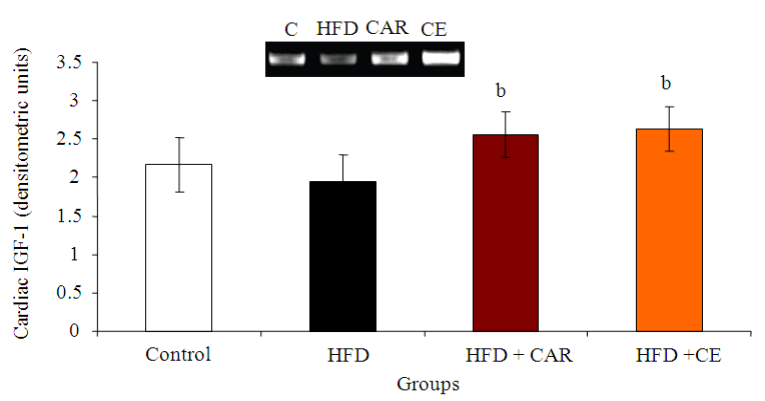

(a)

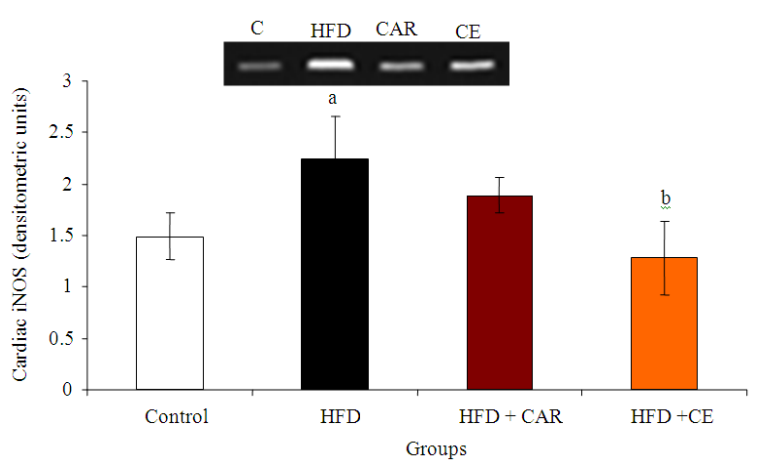

(b)

Fig. 2: Effects of high fructose diet, L-carnitine and cinnamon extract on cardiac IGF-1 (a) and iNOS (b) expression 


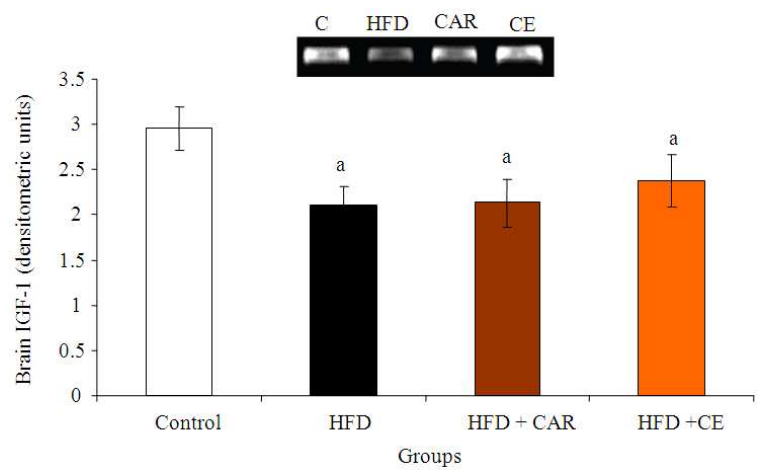

(a)

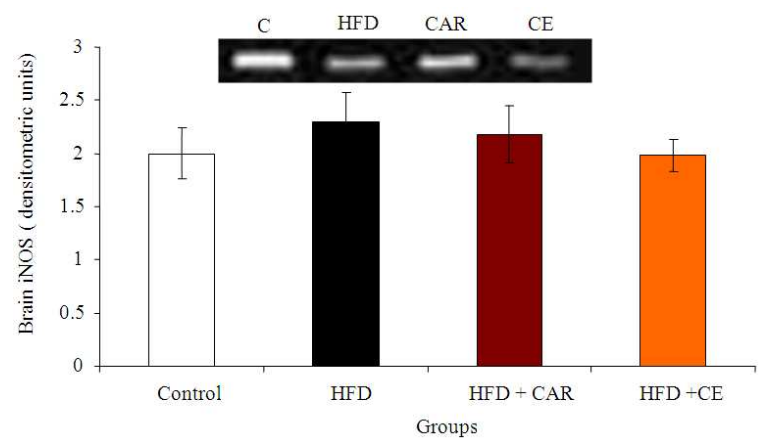

(b)

Fig. 3: Effects of high fructose diet, L-carnitine and cinnamon extract on brain IGF-1 (a) and iNOS (b) expression.

In regard to brain tissue, the expression of IGF-1 was significantly reduced in groups fed HFD $(p<0.0001)$ with non significant changes in the expression of iNOS, compared to control group (Fig. 3).

\section{DISCUSSION}

Metabolism of dietary fructose which occurs mainly in liver differs from that of glucose. Fructose enters the glycolytic pathway at the triose level. This difference in initial metabolism of fructose not only acutely affects carbohydrate metabolism by changing the supply of intermediates, but also induces metabolic adaptation including changes in gene expression (Koo et al., 2008).

The present study illustrates that feeding high fructose diet for 4 weeks caused IR, which characterized by hyperglycemia, hyperinsulinemia and hypertriglyceridemia. These results are in line with those of Nandhini et al. (2002) and Mahfouz et al. (2009).

Homeostatic Model Assessment of Insulin Resistance (HOMA-IR) has emerged as a practical and simple method for estimating insulin resistance. While this method is currently not routinely used as a cardiovascular risk marker, Bertoluci et al. (2010) hypothesized that it could be potentially useful since hyperglycemia and hyperinsulinemia are both related to cardiovascular diseases.

HOMA index was significantly elevated in rats fed the fructose diet. Administration of L-carnitine and CE reduced significantly the HOMA index. The insulin level did not change significantly in the serum of carnitine treated rats, while cinnamon treated rats reduced the level to the control value.

The present work showed significant elevation in the cardiac TG and MDA concentrations as compared to control group. The rate of uptake of lipids, unlike that of glucose, is not regulated by a hormone. Therefore, increased circulating lipids will increase uptake and thereby fatty acid oxidation (Clerk et al., 2002). When the rate of uptake is greater than the rate of oxidation, fatty acids are shuttled to the TG synthesis pathway. Fructose loaded rats, which showed the characteristic features of IR, also displayed an imbalance between the peroxidation process and the antioxidant system. These results agree with (Busserolles et al., 2002), who studied the effects of two weeks of high sucrose on both oxidative stress parameters and stress-related gene expression in rat heart. Both increased TBARS and lower $\mathrm{Cu}-\mathrm{Zn}-\mathrm{SOD}$ activity were found in heart, despite the elevation in $\mathrm{Cu}-\mathrm{Zn}$-SOD mRNA level from high sucrose fed rats compared to rats on a starch diet.

Accumulation of palmitate in cardiomyoblasts produces both increased reactive oxygen and ceramide production, resulting in apoptosis (Wang et al., 2006) which cause cardiac hypertrophy.

The administration of L-carnitine or cinnamon extract to insulin resistant rats mitigated the adverse effect of fructose load on the glycemic status. In addition, they reduced the TG accumulation and the lipid peroxidation in the cardiac tissue.

Rodrigues et al. (1988) and Solfrizzi et al. (2006) stated that L-carnitine supplementation is beneficial for the treatment and prevention of diabetes associated metabolic and cardiac defects, since L-carnitine facilitates the transport of fatty acids across the mitochondrial membrane for eventual oxidation and energy production.

The present results for cinnamon effects are in line with those of Qin et al. (2004) who stated that cinnamon extract fed to animals consuming a highfructose diet prevents the development of the metabolic syndrome. Cinnamon bark was reported to have antioxidant effects by increasing the activities of 
antioxidant enzymes including glutathione Stransferase, superoxide dismutase and catalase in rat livers and hearts (Bell et al., 2008).

The present study attributed the marked reduction in the cardiac level of IRS-1 in rats fed high fructose to the oxidative stress. This in agreement with the findings reported by Bezerra et al. (2000) and Catena et al. (2003) who found significant reductions in hepatic and skeletal muscle IRS-1 tyrosine phosphorylation and receptor numbers in fructose fed rats. In addition, it was observed that exposure of hepatoma cells to an oxidant stress $\left(\mathrm{H}_{2} \mathrm{O}_{2}\right)$ induced increases in phosphorylation at serine 307 and serine 632 of IRS-1 (Bloch-Damti et al., 2003) and this oxidant exposure was associated with degradation of the IRS-1 protein (Potashnik et al., 2003).

L- carnitine and CE improved the IR in the fructose loaded rats. The effect of aqueous extract of cinnamon was accompanied by remarkable increase in the level of IRS-1, while the improvement produced by carnitine was toward the normal control level, but still less than that of cinnamon.

Results of Qin et al. (2004) suggested that CE administration to HFD-fed rats prevents the development of insulin resistance at least in part by enhancing insulin signaling. Water-soluble cinnamon compounds stimulate the autophosphorylation of the insulin receptor and inhibit phosphotyrosine phosphatase activity that inactivates the insulin receptor leading to increased insulin sensitivity (ImparlRadosevich et al., 1998). Also, these polyphenols increase the amount of insulin receptor $\beta$ protein (Cao et al., 2007).

Cardiac cells of diabetic patients do not develop IR to the same extent as seen in skeletal muscle. Some studies have not observed IR in hearts of type II diabetic patients, even when other diabetic tissues of the same patients exhibit significant IR (Utriainen et al., 1998; Jagasia et al., 2001). Thus under conditions of diabetic hyperinsulinemia, the less-resistant heart is being stimulated by relatively high levels of insulin. Consequently, this can explain the non significant reduction observed in the cardiac IGF-1 expression in the studied rats fed HFD, since insulin promotes the action of IGF-1. In the present work supplementation with either L-carnitine or CE increased significantly the IGF-1 expression as compared to HFD group. This elevation may be due to the improved glycemic status. Consequently, IGF-1 enhances insulin sensitivity and increases plasma glucose disappearance and tissue glucose utilization (Conti et al., 2001).

Inflammation induces the expression of iNOS which produces inflammatory mediator NO (Kumar et al., 2004). The expression of iNOS is upregulated by most, if not all, inducers of insulin resistance, including proinflammatory cytokines, free fatty acids (Shimabukuro et al., 1998), hyperglycemia and oxidative stress (Ceriello et al., 2002). In fact, elevated expression of iNOS was observed in skeletal muscle of high fat diet-fed mice (Perreault and Marette, 2001), in heart of Zucker diabetic fatty rats (Zhou et al., 2000) and in skeletal muscle of patients with type 2 diabetes (Torres et al., 2004).

In this study, non significant change in the cardiac level of NO product was observed, despite the elevation of the cardiac iNOS expression associated with IR which induced by feeding rats with high fructose diet. This may be due to either post-transcriptional or translational regulations of iNOS expression or due to deficiency of one or more of cofactors required for NOS activity. Alonso et al. (1997) reported that Tumor Necrosis Factor- $\alpha$ (TNF $\alpha)$ involved in numerous processes in the cardiovascular system, reducing nitricoxide synthase gene expression through posttranscriptional regulation of mRNA stability. The non significant level of cardiac NO may also be partly mediated by scavenging of NO by superoxide anions (generated due to the oxidative stress state) to produce peroxynitrite $\left(\mathrm{NO}_{3}{ }^{-}\right)$. Tetrahydrobiopterin (essential NOS cofactor, BH4) is efficiently oxidized to 7,8dihydrobiopterin $(\mathrm{BH} 2)$ by $\mathrm{NO}_{3}{ }^{-}$in vitro and in vivo. With deficiency of BH4, NOS uncoupling can predominate (Upmacis et al., 2007).

Although L-carnitine and $\mathrm{CE}$ administration improved the expression of iNOS gene, the impact of CE was more pronounced. Kanuri et al. (2009) stated that cinnamon extract was associated with an inhibition of the iNOS mRNA expression found in livers of alcohol-treated animals. These results confirm that the oxidative stress was the reason of that alteration in iNOS expression. Inhibition of iNOS expression has been recently proposed to be a new mechanism of actions of insulin sensitizers (Kohnen et al., 2001). Perreault and Marette (2001) reported that iNOS deficiency protected against high fat diet induced insulin resistance.

A number of studies have been reported concerning the effects of insulin on circulating lipid or lipid contents in the peripheral tissues. However, lipid metabolism in the central nervous system CNS with insulin resistance/diabetes is not well characterized in spite of its potential importance.

This study demonstrates that feeding rats with high fructose diet for 4 weeks has no effect on the brain lipid content.

Brain is the most cholesterol-rich organ, containing approximately $25 \%$ of the cholesterol present in the body and most of its cholesterol is a product of local 
synthesis (Kurban et al., 2007). Kalman et al. (2001) found that, after 10 weeks of hypercholeterolemic diet the rabbits developed significant increase in plasma and liver cholesterol levels. In contrast, the cholesterol content of the brain cortex did not change. In addition, Haris et al. (1993) showed that cholesterol content of brain is not affected by either high fat or high cholesterol diet, which confirms the present results.

This study concerning the expression of brain IGF1 and iNOS illustrated the presence of reduction in the expression of IGF-1 with no change in iNOS gene in both untreated and treated HFD groups.

These results agree with Cheng et al. (2003) who stated that systemic glucose levels possibly regulate IGF-1 expression in brain, given that blood glucose levels were reduced in rats fed caloric restriction diets either carbohydrate-enriched or isocaloric fat-based diet. However brain IGF-1 mRNA levels were equally reduced in both groups, whereas glucose levels were more profoundly reduced in the fat-based diet. He postulated that another unidentified factor related to nutritional status influences brain IGF-1 expression.

Brain inflammation occurs behind the blood-brain barrier and thus differs from inflammation in the periphery by the relative absence of macrophages. Microglia are brain macrophages that produce oxidants and induce expression of iNOS if they detect pathogens or damage (Brown, 2007). This study showed non significant alteration in brain lipid peroxidation, consequently no brain damage.

Concerning all these, we postulate that brain is not affected with the IR state present in that model.

\section{CONCLUSION}

This study illustrates that cinnamon aqueous extract was more potent than L-carnitine in improving the IR.

\section{REFERENCES}

Alonso, J., L. Sanchez de Miguel, M. Monton, S. Casado and A. Lopez-Farre, 1997. Endothelial cytosolic proteins bind to the 3 untranslated region of endothelial nitric oxide synthase mRNA: Regulation by tumor necrosis factor alpha. Mol. Cell. Biol., 17: 5719-5726. PMCID: PMC232420

Anderson, R.A., 2008. Chromium and polyphenols from cinnamon improve insulin sensitivity. Proc. Nutr. Soc., 67: 48-53. DOI: 10.1017/S0029665108006010

Bell, D.S., J.H. O'Keefe and P. Jellinger, 2008. Postprandial dysmetabolism: The missing link between diabetes and cardiovascular events. Endocr. Pract., 14: 112-124. PMID: 18238751
Bertoluci, M.C., A.S. Quadros, R. Sarmento-Leite and B.D. Schaan, 2010. Insulin resistance and triglyceride/HDLc index are associated with coronary artery disease. Diabetol. Metab. Syndr., 2: 11. PMCID: PMC2830967

Bezerra, R.M., M. Ueno, M.S. Silva, D.Q. Tavares and C.R. Carvalho et al., 2000. A high fructose diet affects the early steps of insulin action in muscle and liver of rats. J. Nutr., 130: 1531-1535. PMID: 10827205

Bloch-Damti, A., R. Potashink, J.F. Tanyi, Y. le Marchand-Brustel and A. Rudish et al., 2003. IRS1 protein degradation induced by oxidative stress is associated with distinct time-course of phosphorylation on serine 307 and serine 632 . Diabetologia, 46: A209-A209.

Brown, G.C., 2007. Mechanisms of inflammatory neurodegeneration: INOS and NADPH oxidase. Biochem. Soc. Trans., 35: 1119-1121. DOI: 10.1042/BST0351119

Busserolles, J., W. Zimowska, E. Rock, Y. Rayssiguier and A. Mazur, 2002. Rats fed a high sucrose diet have altered heart antioxidant enzyme activity and gene expression. Life Sci., 71: 1303-1312. DOI: 10.1016/S0024-3205(02)01846-5

Cao, H., M.M. Polansky and R.A. Anderson, 2007. Cinnamon extract and polyphenols affect the expression of tris-tetraprolin, insulin receptor and glucose transporter 4 in mouse 3T3-L1 adipocytes. Arch. Biochem. Biophys., 459: 214-222. DOI: 10.1016/j.abb.2006.12.034

Catena, C., G. Giacchetti, M. Novello, G. Colussi and A. Cavarape et al., 2003. Cellular mechanisms of insulin resistance in rats with fructose-induced hypertension. Am. J. Hypertens, 16: 973-978. DOI: 10.1016/S0895-7061(03)01002-1

Ceriello, A., L. Quagliaro, M.D. Amico, C. di Filippo and R. Marfella et al., 2002. Acute hyperglycemia induces nitrotyrosine formation and apoptosis in perfused heart from rat. Diabetes, 51: 1076-1082. DOI: 10.2337/diabetes.51.4.1076

Cheng, C.M., R.R. Reinhardt, W.H. Lee, G. Joncas and S.C. Patel et al., 2000. Insulin-like growth factor-1 regulates developing brain glucose metabolism. Proc. Natl. Acad. Sci. USA, 97: 10236-10241. PMID: 10954733

Cheng, C.M., B. Kelley, J. Wang, D. Strauss and D.A. Eagles et al., 2003. A ketogenic diet increases brain insulin-like growth factor receptor and glucose transporter gene expression. Endocinology, 144: 2676-2682. DOI: 10.1210/en.2002-0057

Clerk, L.H., S. Rattigan and M.G. Clark, 2002. Lipid infusion impairs physiologic insulin-mediated capillary recruitment and muscle glucose uptake in vivo. Diabetes, 51: 1138-1145. DOI: 10.2337/diabetes.51.4.1138 
Conti, E., F. Andreotti, A. Sciahbasi, P. Riccardi and G. Marra et al., 2001. Markedly reduced insulinlike growth factor-1 in the acute phase of myocardial infarction. J. Am. Coll. Cardiol., 38: 26-32. PMID: 11451284

Dawson, B.K., 2000. Basic and Clinical Biostatistics. 3rd Edn., Appleton and Lange, USA., ISBN: 0838505104, pp: 399.

Deedwania, P.C. and R. Gupta, 2006. Management issues in the metabolic syndrome. J. Assoc. Physicians India, 54: 797-810. PMID: 17214277

Esterbauer, H. and K.H. Cheesman, 1990. Determination of aldehyde lipid peroxidation products: Malonaldehyde and 4-hydroxynonenal. Methods Enzymol., 186: 407-410. PMID: 2233308

Foster, L.B. and R.T. Dunn, 1973. Stable reagents for determination of serum triglycerides by a colorimetric Hantzich condensation method. Clin. Chem., $\quad$ 19: 338-340. http://www.clinchem.org/cgi/reprint/19/3/338.pdf

Frystyk, J. and H. Orskov, 2004. IGF-I, IGF-II, IGFBinding Proteins and Diabetes. In: International Textbook of Diabetes Mellitus, De Fronzo, R.A., Ferrannini, E., H. Keen and P. Zimmet (Eds.). John Wiley, Chichester, pp: 1685-1694.

Fujimoto, M., N. Shimizu, K. Kunii, J.A. Martyn and K. Ueki et al., 2005. A role for iNOS in fasting hyperglycemia and impaired insulin signaling in the liver of obese diabetic mice. Diabetes, 54: 1340-1348. DOI: 10.2337/diabetes.54.5.1340

Haris, K.B., H.R. Cross, W.G. Pond and H.J. Mersmann, 1993. Effect of dietary fat and cholesterol level on tissue cholesterol concentrations of growing pigs selected for high or low serum cholesterol. J. Anim. Sci., 71: 807-810. http://jas.fass.org/cgi/content/abstract/71/4/807

Hill, D.J. and R.D. Milner, 1985. Insulin as a growth factor. Pediatr. Res., 19: 879-886. PMID: 2413420

Hwang, I.S., B.B. Hoffman and G.M. Reaven, 1987. Fructose-induced insulin resistance and hypertension in rats. Hypertension, 10: 512-516. PMID: 3311990

Imparl-Radosevich, J., S. Deas, M.M. Polansky, D.A. Baedke and T.S. Ingebritsen et al., 1998. Regulation of PTP-1 and insulin receptor kinase by fractions from cinnamon: Implications for cinnamon regulation of insulin signaling. Horm. Res., 50: 177-182. DOI: 10.1159/000023270

Jagasia, D., J.M. Whiting, J. Concato, S. Pfau and P.H. McNulty, 2001. Effect of non-insulindependent diabetes mellitus on myocardial insulin responsiveness in patients with ischemic heart disease. Circulation, 103: 1734-1739. PMID: 11282903
Kalman, J., B.J. Kudchodkar, R. Krishnamoorthy, L. Dory and A.G. Lacko et al., 2001. High cholesterol diet down regulates the activity of activator protein-1 but not nuclear factor-kappa B in rabbit brain. Life Sci., 68: 1495-1503. DOI: 10.1016/S0024-3205(01)00955-9.

Kannappan, S., T. Jayaraman, P. Rajasekar, M.K. Ravichandran and C.V. Anuradha, 2006. Cinnamon bark extract improves glucose metabolism and lipid profile in the fructose-fed rat. Singapore Med. J., 47: 858-863. PMID: 16990960

Kanuri, G., S. Weber, V. Volynets, A. Spruss and S.C. Bischoff et al., 2009. Cinnamon extract protects against acute alcohol-induced liver steatosis in mice. J. Nutr., 139: 482-487. DOI: 10.3945/jn.108.100495.

Kohnen, S.L., A.A. Mouithys-Mickalad, G.P. DebyDupont, C.M. Deby and M.L. Lamy et al., 2001. Oxidation of tetrahydrobiopterin by peroxynitrite or oxoferryl species occurs by a radical pathway. Free Radic. Res., 35: 709-721. DOI: 10.1080/10715760100301221

Koo, H., M.A. Wallig, B.H. Chung, T.Y. Nara and B.H. Simon et al., 2008. Dietary fructose induces a wide range of genes with distinct shift in carbohydrate and lipid metabolism in fed and fasted rat liver. Biochim. Biophys. Acta, 1782: 341-348. DOI: 10.1016/j.bbadis.2008.02.007

Kuboki, K., Z.Y. Jiang, N. Takahara, S.W. Ha and M. Igarashi et al., 2000. Regulation of endothelial constitutive nitric oxide synthase gene expression in endothelial cells and in vivo: A specific vascular action of insulin. Circulation, 101: 676-681. PMID: 10673261

Kumar, V., N. Fausto and A. Abbas, 2004. Acute and Chronic Inflammation. In: Robbins and Cotran Pathologic Basis of Disease. 7th Edn., Saunders, Philadelphia, ISBN: 0721601871, pp: 1552.

Kurban, S., I. Mehmetoglu and G. Yilmaz, 2007. Effect of diet oils on lipid levels of the brain of rats. Indian J. Clin. Biochem., 22: 44-47.

Mahfouz, M.H., H.M. Ghanem and M.A. Mohamed, 2009. Therapeutic effect of L-carnitine on sialic acid, soluble Fas (sFas) and other biochemical variables in hyperinsulinemic rats. Life Sci. J., 6: 76-82.

Mahfouz, M.H., H.M. Ghanem and M.A. Mohamed, 2010. Modulation of insulin receptor substrate-1 and some inflammatory variables in hyperinsulinemic rats treated with cinnamon extract. Am. J. Biochem. Biotech., 6: 11-18. DOI: 10.3844/ajbbsp.2010.11.18

Marschner, I., P. Bottermann, F. Erhardt, R. Linke and G. Loffler et al., 1974. Group experiments on the radioimmunological insulin determination. Horm. Metab. Res., 6: 293-296. PMID: 4413601 
Matthews, D.R., J.P. Hosker, A.S. Rudenski, B.A. Naylor and D.F. Treacher et al., 1985. Homeostasis model assessment: Insulin resistance and beta-cell function from fasting plasma glucose and insulin concentrations in man. Diabetologia, 28: 412-419. DOI: 10.1007/BF00280883

Moshage, H., B. Kok, J. Huizenga and P. Junsen, 1995. Nitrite and nitrate determinations in plasma: A critical evaluation. Clin. Chem., 41: 892-896. PMID: 7768008

Nandhini, A.T., S.D. Balakrishnan and C.V. Anuradha, 2002. Taurine improves lipid profile in rats fed a high fructose-diet. Nutr. Res., 22: 343-354.

Perreault, M. and A. Marette, 2001. Targeted disruption of inducible nitric oxide synthase protects against obesity-linked insulin resistance in muscle. Nat. Med., 7: 1138-1143. PMID: 11590438

Potashnik, R., A. Bloch-Damti, N. Bashan and A. Rudish, 2003. IRS-1 degradation and increased serine phosphorylation can not predict the degree of metabolic insulin resistance induced by oxidative stress. Diabetologia, 46: 639-648. DOI: 10.1007/s00125-003-1097-5

Qin, B., M. Nagasaki, M. Ren, G. Bajotto and Y. Oshida et al., 2004. Cinnamon extract prevents the insulin resistance induced by a high-fructose diet. Horm. Metab. Res., 36: 119-125. DOI: 10.1055/s-2004-814223.

Rajasekar, P. and C.V. Anuradha, 2007. Effect of Lcarnitine on skeletal muscle lipids and oxidative stress in rats fed high-fructose diet. Exp. Diabetes Res., 2007: 727-741. PMID: 17641743

Refaie, F.M., A.Y. Esmat, S.M. Abdel Gawad, A.M. Ibrahim and M.A. Mohamed, 2005. The antihyperlipidemic activities of $4(3 \mathrm{H})$ quinazolinone and two halogenated derivatives in rats. Lipids Health Dis., 4: 22-32. DOI: 10.1186/1476-511X-4-22

Rodrigues, B., H. Xiang and J.H. McNill, 1988. Effect of L-carnitine treatment on lipid metabolism and cardiac performance in chronically diabetic rats. Diabetes, 37: 1358-1364. DOI: 10.2337/diabetes.37.10.1358

Shaker, O.G., D.A. Sourour and M. Taha, 2009. Effects of statins on insulin-like growth factor-1 gene expression in fructose induced metabolic syndrome in rats. Open Endocrinol. J., 3: 28-33. http://www.bentham.org/open/toej/articles/V003/2 8TOEJ.pdf

Shimabukuro, M., M. Higa, Y.T. Zhou, M.Y. Wang and C.B. Newgard et al., 1998. Lipoapoptosis in betacells of obese prediabetic fa/fa rats: Role of serine palmitoyl transferase overexpression. J. Biol. Chem., 273: 32487-32490. DOI: 10.1074/jbc.273.49.32487
Shinozaki, K., A. Kashiwagi, Y. Nishio, T. Okamura and Y. Yoshida et al., 1999. Abnormal biopterin metabolism is a major cause of impaired endothelium-dependent relaxation through nitric oxide/O2 imbalance in insulin-resistant rat aorta. Diabetes, 48: 2437-2445. DOI: 10.2337/diabetes.48.12.2437

Solfrizzi, V., C. Capurso, A.M. Colacicco, A.D. Introno and C. Fontana et al., 2006. Efficacy and tolerability of combined treatment with L-carnitine and simvastatin in lowering lipoprotein (a) serum levels in patients with type 2 diabetes mellitus. Atherosclerosis, 188: 455-461. DOI: 10.1016/j.atherosclerosis.2005.11.024

Taimor, G., A. Rakow and H.M. Piper, 2001. Transcription Activator Protein 1 (AP-1) mediates NO-induced apoptosis of adult cardiomyocytes. FASEB J., 15: 2518-2520. DOI: 10.1096/fj.010353fje

Torres, S.H., J.B. de Sanctis, M. de L. Briceno, N. Hernandez and H.J. Finol, 2004. Inflammation and nitric oxide production in skeletal muscle of type 2 diabetic patients. J. Endocrinol., 181: 419-427. PMID: 15171690

Upmacis, R.K., M.J. Crabtree, R.S. Deeb, H. Shen and P.B. Lane et al., 2007. Profound biopterin oxidation and protein tyrosine nitration in tissues of ApoE-null mice on an atherogenic diet: Contribution of inducible nitric oxide synthase. Am. J. Physiol. Heart Circ. Physiol., 293: 2878-2887. DOI: 10.1152/ajpheart.01144

Utriainen, T., T. Takala, M. Luotolahti, T. Ronnemaa and H. Laine et al., 1998. Insulin resistance characterizes glucose uptake in skeletal muscle but not in the heart in NIDDM. Diabetologia, 41: 555-559. PMID: 9628273

Wang, J., Y. Song, Q. Wang, P.M. Kralik and P.N. Epstein, 2006. Causes and characteristics of diabetic cardiomyopathy. Rev. Diabet. Study, 3: 108-117. DOI: 10.1900/RDS.2006.3.108

Yousef, M., M. Haroun, M. El-Masry and R. Ateia, 2006. Biochemical and immunological study on the effects of barley and its components as hypoglycemic agents in diabetic rats. Am. J. Biochem. Biotech., 2: 1-8. DOI: 10.3844/ajbbsp.2006.1.8

Zhou, Y.T., P. Grayburn, A. Karim, M. Shimabukuro and M. Higa et al., 2000. Lipotoxic heart disease in obese rats: Implications for human obesity. Proc. Natl. Acad. Sci. USA., 97: 1784-89. PMID: 10677535 